\title{
A chimeric vacuolar $\mathrm{Na}^{+} / \mathrm{H}^{+}$antiporter gene evolved by DNA family shuffling confers increased salt tolerance in yeast
}

\author{
Guangxia $\mathrm{Wu}^{\mathrm{a}, \mathrm{b}}$, Gang Wanga ${ }^{\mathrm{a}, *}$, Jing $\mathrm{Ji}^{\mathrm{a}}$, Yong $\mathrm{Li}^{\mathrm{c}}$, Hailing $\mathrm{Gao}^{\mathrm{a}}$, \\ Jiang $\mathrm{Wu}^{\mathrm{b}, \mathrm{d}}$, Wenzhu Guan ${ }^{\mathrm{a}, \mathrm{b}}$ \\ a School of Environmental Science and Engineering, Tianjin University, Tianjin 300072, People's Republic of China \\ b School of Chemical Engineering and Technology, Tianjin University, Tianjin 300072, People's Republic of China \\ ${ }^{\mathrm{c}}$ Key Laboratory of Ecosystem Network Observation and Modeling, Institute of Geographic Sciences and Natural Resources Research, \\ Chinese Academy of Science, Beijing 100101, People's Republic of China \\ d Department of Agronomy, Tianjin Agricultural University, Tianjin 300384, People's Republic of China
}

\section{A R T I C L E I N F O}

\section{Article history:}

Received 21 October 2014

Received in revised form 22 February 2015

Accepted 25 February 2015

Available online 14 March 2015

\section{Keywords:}

DNA family shuffling

$\mathrm{Na}^{+} / \mathrm{H}^{+}$antiporter

Salt tolerance

Yeast

\begin{abstract}
A B S T R A C T
The vacuolar $\mathrm{Na}^{+} / \mathrm{H}^{+}$antiporter plays an important role in maintaining ionic homeostasis and the osmotic balance of the cell with the environment by sequestering excessive cytoplasmic $\mathrm{Na}^{+}$into the vacuole. However, the relatively low $\mathrm{Na}^{+} / \mathrm{H}^{+}$exchange efficiency of the identified $\mathrm{Na}^{+} / \mathrm{H}^{+}$antiporter could limit its application in the molecular breeding of salt tolerant crops. In this study, DNA family shuffling was used to create chimeric $\mathrm{Na}^{+} / \mathrm{H}^{+}$antiporters with improved transport activity. Two homologous $\mathrm{Na}^{+} / \mathrm{H}^{+}$ antiporters from halophytes Salicornia europaea (SeNHX1) and Suaeda salsa (SsNHX1) were shuffled to generate a diverse gene library. Using a high-throughput screening system of yeast complementation, a novel chimeric protein SseNHX1 carrying 12 crossover positions and 2 point mutations at amino acid level was selected. Expression of SseNHX1 in yeast mutant exhibited approximately $46 \%$ and $22 \%$ higher salt tolerance ability in yeast growth test than that of SsNHX1and SeNHX1, respectively. Measurements of the ion contents demonstrated that SseNHX1 protein in yeast cells accumulated more $\mathrm{Na}^{+}$and slightly more $\mathrm{K}^{+}$than the parental proteins did. Furthermore, this chimera also conferred increased tolerance to $\mathrm{LiCl}$ and a similar tolerance to hygromycin B compared with the parental proteins in yeast.
\end{abstract}

(c) 2015 Elsevier B.V. All rights reserved.

\section{Introduction}

Soil salinity is one of the most serious threats to world agriculture, particularly in irrigated lands. The relatively high solute concentrations in the soil would seriously disrupt the normal metabolism of plants. To cope with salt stress and the toxic effect of sodium, plants have developed several adaptive mechanisms and one of the most effective strategies is to regulate cellular ion homeostasis involving excessive cytosolic $\mathrm{Na}^{+}$exclusion and vacuolar compartmentalization of toxic ions from cytosol mediated by $\mathrm{Na}^{+} / \mathrm{H}^{+}$antiporters (Quintero et al., 2002; Yokoi et al., 2002). In plants, $\mathrm{Na}^{+} / \mathrm{H}^{+}$antiporters are located both in the plasma membrane (SOS1-type) and tonoplast (NHX1-type) where they function to catalyze the exchange of $\mathrm{Na}^{+}$and $\mathrm{H}^{+}$across membranes using a $\mathrm{H}^{+}$-motive force created by proton pumps as the driving power (Blumwald et al., 2000; Fukuda et al., 2004).

\footnotetext{
* Corresponding author. Tel.: +86 022 87402200; fax: +86 02287402200 .

E-mail address: gangwang@tju.edu.cn (G. Wang).
}

The compartmentation of $\mathrm{Na}^{+}$into the vacuole is a critical process in salt tolerance, which provides an efficient mechanism to avert the deleterious effects of $\mathrm{Na}^{+}$in the cytosol, while mediating vacuolar osmotic adjustment that facilitates water uptake into cells (Leidi et al., 2010). The ability to compartmentalize $\mathrm{Na}^{+}$is considered to be a salt adaptation not only conserved in halophytes but also in glycophytes (Hasegawa et al., 2000). To date, a large number of cDNAs encoding vacuolar $\mathrm{Na}^{+} / \mathrm{H}^{+}$antiporter have been isolated and increasing evidence has demonstrated that overexpressing vacuolar $\mathrm{Na}^{+} / \mathrm{H}^{+}$antiporter gene improved salt tolerance in various plant species (Chen et al., 2007a, 2007b; Fukuda et al., 2011; Li et al., 2011; Zhang, 2001). All these studies indicate that an improved capacity for vacuolar $\mathrm{Na}^{+}$sequestration is vital to salinity tolerance and overexpression of vacuolar $\mathrm{Na}^{+} / \mathrm{H}^{+}$antiporters provides an approach that can contribute to the molecular breeding of salt-tolerant plants. However, the relatively low $\mathrm{Na}^{+} / \mathrm{H}^{+}$exchange efficiency of the cloned $\mathrm{Na}^{+} / \mathrm{H}^{+}$antiporters is a limiting factor in the application of these antiporter genes for crop breeding. One of the reasons for this may be that salt-sensitive plants showed weak induction of both $\mathrm{Na}^{+} / \mathrm{H}^{+}$antiporter expression and activity 
in response to $\mathrm{NaCl}$ treatment. Therefore, creating new vacuolar $\mathrm{Na}^{+} / \mathrm{H}^{+}$antiporter gene from halophytes and molecular evolution of the identified antiporter with high strong salt tolerance ability are urgently needed for plant molecular breeding of salt tolerance.

DNA family shuffling is a developed technique for molecular directed evolution in vitro, which generates a library of chimeras by recombination of homologous sequences and combing useful mutation for individual genes. It mimicks and extends traditional breeding methods by recombining the same gene from related species or related genes from a single species in a single DNA shuffling reaction. Compared with other molecular breeding technology, DNA family shuffling can not only significantly accelerate the accumulation of beneficial mutations, but also efficiently increase the diversity of the target protein (Kikuchi and Harayama, 2002). In recent years, DNA family shuffling has widespread practical applications. For example, DNA family shuffling has been successfully used to improve activity and thermostability in lipase (Akbulut et al., 2013; Suen et al., 2004), improve activity and stability in endo- $\beta$ - 1,4 -mannanase (Wang et al., 2013a), extend diversity in cytochrome P450 (Rosic et al., 2007) and alter substrate specificity in avidin (Niederhauser et al., 2012; Wang et al., 2013b). At the same time, the theoretical and technics of DNA shuffling have also been applied to improve the activity of $\mathrm{Na}^{+} / \mathrm{H}^{+}$antiporters. It was reported that a novel plant vacuolar $\mathrm{Na}^{+} / \mathrm{H}^{+}$antiporter AtNHXS1 was demonstrated about 1 -fold improvement in salt tolerance via DNA shuffling of AtNHX1 from Arabidopsis thaliana (Xu et al., 2010). Subsequently, their laboratory conducted DNA family shuffling of AtNHX1 with wide type vacuolar $\mathrm{Na}^{+} / \mathrm{H}^{+}$antiporters from oryza sativa (OsNHXI) and Dendranthema morifolium (DmNHXI) (Zhang et al., 2012). However, previous works focused on a single gene or multiple genes from glycophytes which have low salt tolerance range and limited the amount of improvement available.

In this study, we chose two strong $\mathrm{Na}^{+} / \mathrm{H}^{+}$antiporter genes from halophytes Salicornia europaea (SeNHX1, GenBank accession no. AY131235) and Suaeda salsa (SsNHX1, GenBank accession no. AY261806) as templates (parents) to conduct DNA family shuffling. Chimeric $\mathrm{Na}^{+} / \mathrm{H}^{+}$antiporters with higher ability of salt tolerance were identified by yeast complement system screening. Finally, one novel chimera (named SseNHX1) was obtained and demonstrated improvement salt tolerance in yeast.

\section{Materials and methods}

\subsection{Yeast strains and medium}

Saccharomyces cerevisiae wild type strain W303-1B (MAT $\alpha$,ra31,leu2-3,trp1-1,his3-11,ade2-1,can1-100) and the salt-sensitive

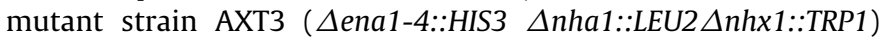
(Quintero et al., 2000), derived from W303-1B were used. Yeast cells were grown in YPD (1\% yeast extract, $2 \%$ peptone, $2 \%$ glucose), and selected on SD media ( $0.67 \%$ yeast nitrogen base, $2 \%$ glucose, and the appropriate amino acid). Cation tolerance tests were performed in the alkali cation-free medium AP $(10 \mathrm{mM}$ arginine, $8 \mathrm{mM}$ phosphoric acid, $2 \mathrm{mM} \mathrm{MgSO}_{4}, 1 \mathrm{mM} \mathrm{KCl}, 0.2 \mathrm{mM} \mathrm{CaCl}_{2}, 2 \%$ glucose, trace vitamins and minerals, at pH 5.6 with arginine and phosphoric acid) supplemented with or without $\mathrm{NaCl}$ or $\mathrm{LiCl}$ as indicated. Resistance to $\mathrm{KCl}$ or hygromycin B (Hyg B) was assayed in YPD medium. For induction of antiporter expression in cells carrying plasmids with antiporter genes under control of the GAL1 promoter, glucose $(2 \%)$ was replaced by galactose $(2 \%)$ in the growth medium.

\subsection{DNA family shuffling and library construction}

DNA family shuffling was performed as previously described with slight modifications (Stemmer, 1994; Zhao and Arnold, 1997).
Table 1

Primers used in the present study.

\begin{tabular}{lll}
\hline Primer & Oligonucleotide sequences $\left(5^{\prime}-3^{\prime}\right)$ & Restriction site \\
\hline ssF & CGCGGATCCATGTGGTCACAGTTAAGCTC & BamH I \\
ssR & ACGCGTCGACTTATGTTCTCTGTGACAAATTAGTGG & Sal I \\
seF & CGCGGATCCATGTTGTCACAATTGAGCTC & Bam H I \\
seR & ACGCGTCGACTGTTCTGTCTAGCAAATTGTC & Sal I \\
\hline
\end{tabular}

The introduced restriction sites are underlined.

All the assembly and DNA amplification steps in the whole shuffling process were performed with Taq Plus DNA Polymerase (Tiangen, China), which is a mixture of Pfu and Taq DNA polymerase. Briefly, the DNA family shuffling procedure consists of four steps, that is parental templates preparation, DNase I digestion, primer-less PCR and primer PCR. Firstly, two DNA fragments containing the $\mathrm{Na}^{+} / \mathrm{H}^{+}$antiporter genes were amplified by conventional PCR from plasmids pGH-SsNHX1 and pMD18T-SeNHX1 using the primers $\mathrm{ssF} / \mathrm{ssR}$ and seF/seR, respectively (Table 1 ). Fragments of $\approx 1.7 \mathrm{~kb}$ used as substrates for shuffling were purified from $0.8 \%$ agarose gels using QIAEX II gel extraction kit (QIAGEN, Chatsworth, CA). Equal amounts of the two gene preparations were mixed for a total of $\approx 3 \mu \mathrm{g}$. This mixture was equilibrated for $5 \mathrm{~min}$ at $15^{\circ} \mathrm{C}$ before 0.3 U DNase I (10 U/ $\mathrm{LL}$; order No. EN0525 Fermentas, St. Leon-Rot, Germany) was added. The digestion was done in the presence of $2 \mathrm{mM} \mathrm{Mn}^{2+}$ for $2 \mathrm{~min}$ at $15^{\circ} \mathrm{C}$ and terminated by heating at $90^{\circ} \mathrm{C}$ for $10 \mathrm{~min}$. The digested DNA was electrophoresed as a smear in a $2 \%$ agarose gel. That the desired DNA fragments between 100 and $200 \mathrm{bp}$ were isolated and purified as described above. Primerless PCR was performed in mixture containing 2.5 U Taq Plus DNA Polymerase, $1 \times$ Taq Plus buffer, $1 \mu \mathrm{g}$ of the fragments mixture, $0.2 \mathrm{mmol} / \mathrm{L} \mathrm{dNTP}$ with a total volume of $50 \mu \mathrm{L}$. The reaction was carried out under the conditions of $94^{\circ} \mathrm{C}$ for $1 \mathrm{~min}, 40$ cycles of $94{ }^{\circ} \mathrm{C}$ for $30 \mathrm{~s}, 50^{\circ} \mathrm{C}$ for $30 \mathrm{~s}$ and $72^{\circ} \mathrm{C}$ for $30 \mathrm{~s}$, and a final incubation at $72{ }^{\circ} \mathrm{C}$ for $8 \mathrm{~min}$. One microlitre of this reaction was used as a template to amplify the full-length genes using a parallel set of primers (ssF/ssR or seF/seR) or a "skew" set of primers (ssF/seR or seF/ssR). The PCR program was $4 \mathrm{~min}$ at $94^{\circ} \mathrm{C}$ followed by 30 cycles of $30 \mathrm{~s}$ at $94^{\circ} \mathrm{C}, 30 \mathrm{~s}$ at $56^{\circ} \mathrm{C}, 1 \mathrm{~min} 40 \mathrm{~s}$ at $72^{\circ} \mathrm{C}$, and finally $8 \mathrm{~min}$ at $72{ }^{\circ} \mathrm{C}$. A single product of the correct size was obtained.

To generate the mutant library, the mutated PCR products of the full-length gene were digested by BamH I and Sal I before purification and ligated into the yeast-E. coli shuttle vector pYES2 (Invitrogen, Carlsbad, USA) which was digested by the same enzymes. The ligation products were used to transform competent $E$. coli $\mathrm{DH} 5 \alpha$ cells by electroporation. All the resulting colonies were washed down with sterile water, then plasmid DNA was extracted from the pooled E. coli library and subsequently transformed into the triple-deletion yeast mutant AXT3 using lithium acetate method (Gietz and Woods, 2002).

\subsection{Screening for high salt tolerance yeast clones}

Transformed yeast colonies harboring shuffled $\mathrm{Na}^{+} / \mathrm{H}^{+}$ antiporter genes were primarily screened on the AP selective medium supplemented with $100 \mathrm{mM} \mathrm{NaCl}$. Plates were then incubated for 4 days at $30^{\circ} \mathrm{C}$. The selected yeast clones from the first screening were cultured in liquid AP to OD600 $=0.5,5 \mu \mathrm{L}$ of the cells were loaded onto AP medium supplemented with 125 and $150 \mathrm{mM} \mathrm{NaCl}$ for the second selection.

\subsection{Salt tolerance test}

To compare salt tolerance of the hybrid $\mathrm{Na}^{+} / \mathrm{H}^{+}$antiporter gene with that of the parental genes, the ORF of SsNHX1 and SeNHX1 were also constructed into the yeast express vector pYES2 (driven 
by a GAL1 promoter) using BamH I and Sal I. The constructs were also introduced into the AXT3 mutant strain by separate transformation. As control, the wild type W303-1B and mutant AXT3 were all transformed with empty pYES2. The transformants were selected on SD medium lacking uracil.

For drop tests, transformed yeast cells were pre-cultured overnight in liquid SD media, and protein expression was induced by addition of $2 \%$ galactose. Six hours later, cells were adjusted to the same initial OD600 $=1.0$. Serial tenfold dilutions were prepared, and $5 \mu \mathrm{L}$ of each dilution was spotted on AP agar plates supplemented with different concentrations of $\mathrm{NaCl}$. Growth was recorded over a period of 4 days.

For growth assays, $50 \mu \mathrm{L}$ of the same strain seed culture (OD600 $=1$ ) were grown in $4 \mathrm{ml}$ of AP medium supplemented with $0,25,50,75,100,150,175$ or $200 \mathrm{mM} \mathrm{NaCl}$ at $30^{\circ} \mathrm{C}$ for $48 \mathrm{~h}$ with shaking $(200 \mathrm{rpm})$. Cell growth was then determined by OD600 measurements. There were three replications for each treatment.

For ion content measurements, yeast cells were grown in AP medium to an OD600 of approximately 0.3 , then resuspended into the same medium supplemented with $70 \mathrm{mM} \mathrm{NaCl}$ and continued to culture $6 \mathrm{~h}$. Yeast cells were harvested by centrifugation, washed twice with ice-cold $10 \mathrm{mM} \mathrm{MgCl}_{2}, 10 \mathrm{mM} \mathrm{CaCl}_{2}, 1 \mathrm{mM} \mathrm{HEPES}$, and extracted with acid as described before (Montiel and Ramos, 2007). Ion contents of the samples were determined by inductively coupled plasma atomic emission spectrometry (ICP-AES, Thermo).

\section{5. $\mathrm{K}^{+}, \mathrm{Li}^{+}$and Hyg B tolerance test}

Yeast cells were prepared under the same conditions for drop test of salt tolerance experiment. $5 \mu \mathrm{L}$ of each dilution was spotted on AP or YPD agar plates supplemented with or without $\mathrm{KCl}$, $\mathrm{LiCl}$ or Hyg B as indicated. Growth was recorded over a period of 3 days.

\subsection{Sequence analysis}

In order to identify the substituted residues, the sequence alignments of SseNHX1 with SsNHX1 and SeNHX1 were performed by the CLUSTAL X program (Thompson et al., 2002). Protein secondary structure was predicted and two dimensional models of alpha helical transmembrane proteins was created by using online available software TMRPres2D (Omasits et al., 2014).

\subsection{Statistical analysis}

The statistical differences between the controls and shuffled gene SseNHX1 were assessed based on the analysis of variance ANOVA using SPSS (Ver. 15, Chicago, USA). Differences were considered significant at a probability level of $P<0.05$.

\section{Results}

\subsection{DNA family shuffling and screening of the library}

The parental genes SsNHX1 and SeNHX1 were amplified by regular PCR and digested by DNase I into small fragments. Gel-purified $100-200$ bp fragments were reassembled to a faintly visible single PCR product of the correct size. Reassembled products from primerless PCR were used as templates for primer PCR. As a result, the clear main gene bands on agarose gel corresponding to the expected size were obtained with different primers. The detection of products in the process of DNA family shuffling was shown as Fig. 1.

DNA family shuffling of SsNHX1 and SeNHX1 resulted in a library of $10^{5}$ colonies in E. coli. Plasmid DNA was isolated from this E. coli library and used to transform salt sensitive yeast strain AXT3 for screening improved forms of the vacuolar antiporter with the $\mathrm{NaCl}$ selective pressure. Approximately 200 colonies with better grown (as judged by eye) were selected for the second screening step, in which higher salt concentrations for yeast growth were applied. From these, one clone, named SseNHX1, showed more resistant to salt than all the other selective clones (Fig. 2a).

\subsection{Increased salt tolerance conferred by shuffled SseNHX1}

To compare the capacity of mediating salt tolerance in yeast expressing the shuffled SseNHX1 gene with that of the parental genes, the three $\mathrm{Na}^{+} / \mathrm{H}^{+}$antiporter genes were expressed separately in the salt-sensitive AXT3 yeast mutant. The different yeast strains were grown on the AP medium supplemented with different $\mathrm{NaCl}$ concentrations. As shown in Fig. 2b, no differences in yeast cell growth were detected given the presence or absence of $\mathrm{Na}^{+} / \mathrm{H}^{+}$ antiporter genes on a $\mathrm{NaCl}$ free medium. Since $\mathrm{Na}^{+}$sensitivity of the yeast mutant strain AXT3, it was seen to be noticeably suppressed with increasing salt concentration compared with that of the wild type W303-1B. Expression of SsNHX1 or SeNHX1 in AXT3 partially recovered the mutant phenotype, but the recovery was not as great as SseNHX1. Complementation with SseNHX1 expression was observed up to $10^{-2}$ in the presence of $150 \mathrm{mM} \mathrm{NaCl}$, whereas complementation with the parental gene expression were only able to increase population growth rates at $10^{-1}$ in the same growth medium. These results accorded with the liquid salt tolerance test which showed that the salt tolerance of yeast expressing SseNHX1 was improved about $46 \%$ and $22 \%$ as compared to the yeast carrying SsNHX1 and SeNHX1, respectively (Fig. 2c). To determine whether SseNHX1 sequester greater $\mathrm{Na}^{+}$to yeast cells, the total intracellular ion contents of the yeast cells grown in AP medium with $70 \mathrm{mM} \mathrm{NaCl}$ and $1 \mathrm{mM} \mathrm{KCl}$ were measured. As shown in Fig. 2d and e, the yeast mutant harboring SseNHX1 was able to accumulate 1.2 and 1.4 -fold $\mathrm{Na}^{+}$than that of yeast harboring the parents,

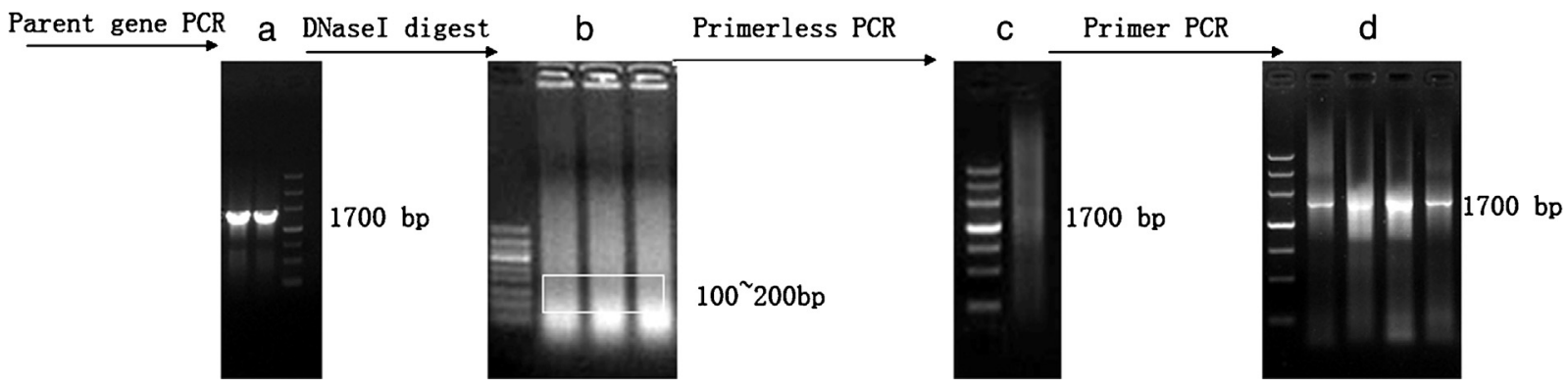

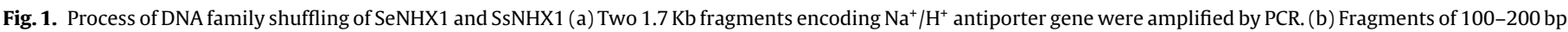

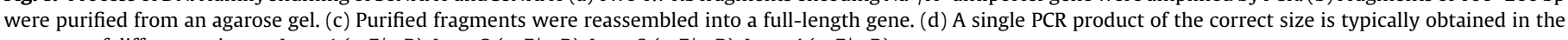
presence of different primers. Lane 1 (ssF/ssR), Lane 2 (seF/seR), Lane 3 (ssF/seR), Lane 4 (seF/ssR). 
a
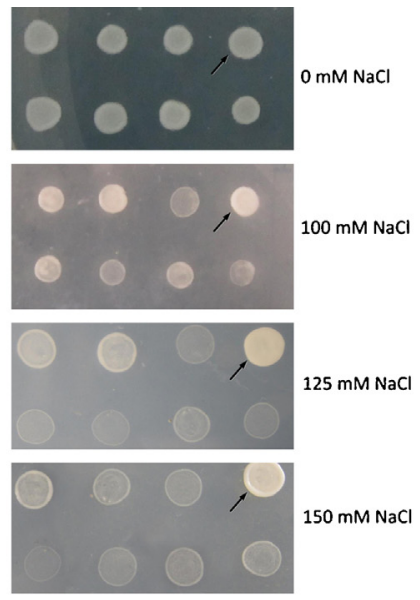

b

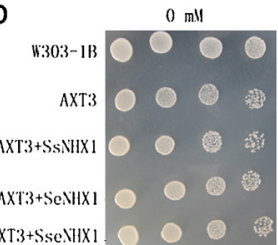

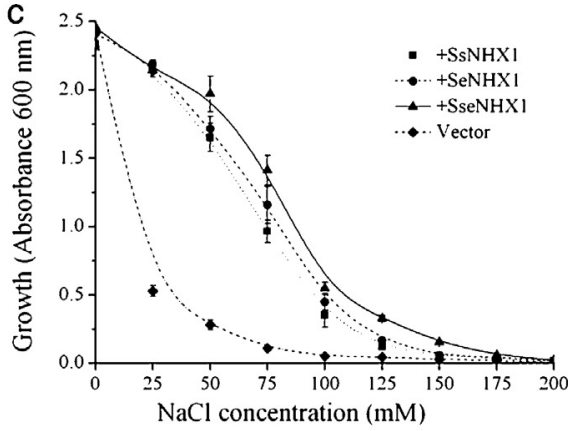

$\mathrm{NaCl}$ concentration $(\mathrm{mM})$ d

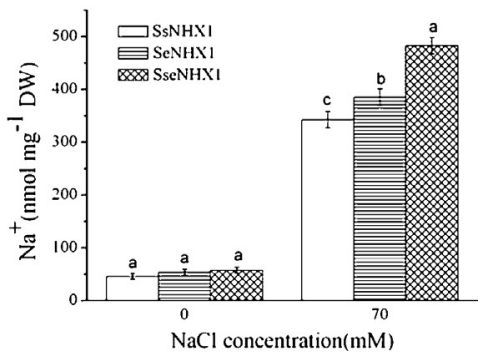

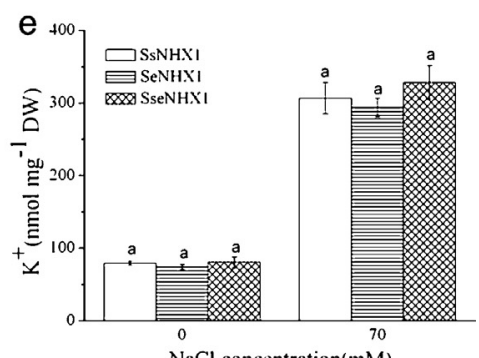

$\mathrm{NaCl}$ concentration $(\mathrm{mM})$

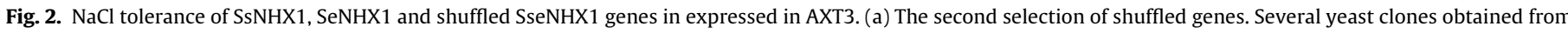

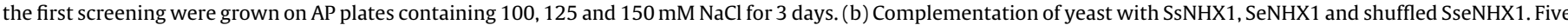

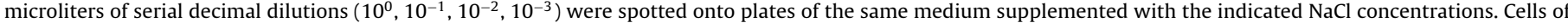

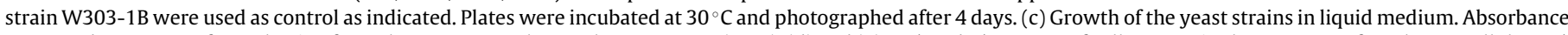

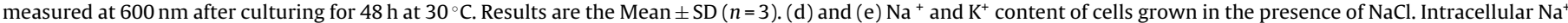
and $\mathrm{K}^{+}$contents were determined in cells grown in AP medium with $70 \mathrm{mM} \mathrm{NaCl}$ until mid-exponential growth phase. Results are the Mean \pm SD $(n=3)$.

while there were no noticeable differences between SseNHX1 and parental proteins with regard to $\mathrm{K}^{+}$content. These results would suggest that the yeast strain expressing SseNHX1 have a higher ability to sequester $\mathrm{Na}^{+}$into the vacuole than that from parental genes, and subsequently a enhanced $\mathrm{NaCl}$ tolerance.

\subsection{SseNHX1 conferred resistance to $\mathrm{KCl}, \mathrm{LiCl}$ and $\mathrm{Hyg} \mathrm{B}$ in yeast mutant}

In an attempt to characterize other cation $\left(\mathrm{Li}^{+}\right.$and $\left.\mathrm{K}^{+}\right)$sensitivity of AXT3 expressing with SseNHX1 and parental NHX1 genes, similar complementation studies were carried out for each one of these genes. As shown in Fig. 3a, AXT3 mutant was hypersensitive to $\mathrm{LiCl}$ and failed to grow in the AP medium containing $3 \mathrm{mM} \mathrm{LiCl}$ while the wild type strain grew vigorously. Although expression of SsNHX1 and SeNHX1 also partly recovered tolerance to $\mathrm{Li}^{+}$, the recovery capacities of SsNHX1 and SeNHX1 were not as great as that of SseNHX1, suggesting that SseNHX1 also conferred $\mathrm{Li}^{+}$tolerance. Overexpression of all NHX1 genes can, to a certain extent, increase the tolerance to $\mathrm{KCl}$ (Fig. $3 \mathrm{~b}$ ). These results suggested that SseNHX1 not only enhanced $\mathrm{Na}^{+}$tolerance of yeast but also, to a relatively lesser extent, facilitated $\mathrm{K}^{+}$and $\mathrm{Li}^{+}$homeostasis.

Vacuolar $\mathrm{Na}^{+} / \mathrm{H}^{+}$antiporters have function for resistance to various toxic cations, including Hyg B and Hyg B sensitivity of yeast nhx1 mutant has been widely used in functional complementation studies to identify $\mathrm{Na}^{+} / \mathrm{H}^{+}$antiporters (Gaxiola et al., 1999; Shi et al., 2002). Clearly, the growth of the mutant yeast strain complemented with the different $\mathrm{Na}^{+} / \mathrm{H}^{+}$antiporter genes was significantly different than that with the control plasmids (Fig. 3b). However, there appears to be no obvious difference among the $\mathrm{Na}^{+} / \mathrm{H}^{+}$antiporter genes in the degree of the complementation with $\mathrm{Hyg} \mathrm{B}$, which indicated that the introduced mutations did not change the tolerance of $\mathrm{Na}^{+} / \mathrm{H}^{+}$antiporter to Hyg B (Fig. 3b).
Table 2

DNA and amino acid substitutions in SseNHX1 mutant compared with SsNHX1.

\begin{tabular}{lll}
\hline DNA substitution & Amino acid substitution & Property \\
\hline GCA $\rightarrow$ TAT & $10 \mathrm{~A} \rightarrow 10 \mathrm{Y}$ & Random mutation \\
GTT $\rightarrow$ CTA & $16 \mathrm{~V} \rightarrow 16 \mathrm{~L}$ & Recombination \\
GTT $\rightarrow$ GCG & $24 \mathrm{~V} \rightarrow 24 \mathrm{~A}$ & Recombination \\
TTT $\rightarrow$ TCT & $117 \mathrm{~F} \rightarrow 117 \mathrm{~S}$ & Random mutation \\
CTT $\rightarrow$ TAT & $150 \mathrm{~L} \rightarrow 150 \mathrm{Y}$ & Recombination \\
CAC $\rightarrow$ AAT & $206 \mathrm{H} \rightarrow 206 \mathrm{~N}$ & Recombination \\
GCT $\rightarrow$ ATG & $402 \mathrm{~V} \rightarrow 398 \mathrm{M}$ & Recombination \\
TCA $\rightarrow$ ACG & $410 \mathrm{~S} \rightarrow 406 \mathrm{~T}$ & Recombination \\
TTT $\rightarrow$ TAC & $540 \mathrm{~F} \rightarrow 536 \mathrm{Y}$ & Recombination \\
ACC $\rightarrow$ ATT & $546 \mathrm{~T} \rightarrow 542 \mathrm{I}$ & Recombination \\
AGC $\rightarrow$ AAC & $549 \mathrm{~S} \rightarrow 545 \mathrm{~N}$ & Recombination \\
ACT $\rightarrow$ GAC & $551 \mathrm{~T} \rightarrow 547 \mathrm{D}$ & Recombination \\
TCA $\rightarrow$ CTA & $554 \mathrm{~S} \rightarrow 550 \mathrm{~L}$ & Recombination \\
CAG $\rightarrow$ GAC & $555 \mathrm{Q} \rightarrow 551 \mathrm{D}$ & Recombination \\
AGAATTGCCTAC & $210-213 \mathrm{RIAY}$ & Deletion \\
\hline
\end{tabular}

\subsection{Sequence analysis of shuffled SseNHX1}

The shuffled SseNHX1 clone was sequenced and compared to those of the parental genes. Nucleotide sequence alignment identified numerous nucleotide substitutions (data not shown). Most of these nucleotide substitutions resulted in silent mutations, but a few resulted in amino acid residue substitutions (mutations). The amino acid sequence alignment with its parents revealed that the most amino acid sites were conserved (Fig. 4a). Based on sequence analyses, chimeric SseNHX1 was found to be well-shuffled and the different amino acid elements from two parents were presented in Fig. 4a. The mutant DNA sequences and the identities of the deduced amino acid sequence changes in the SseNHX1 are listed in Table 2. Sequencing revealed that this chimera with up to 17 crossovers, producing up to 12 amino acid substitutions compared with the more similar parent SsNHX1 (Table 2). The 12 amino acid 


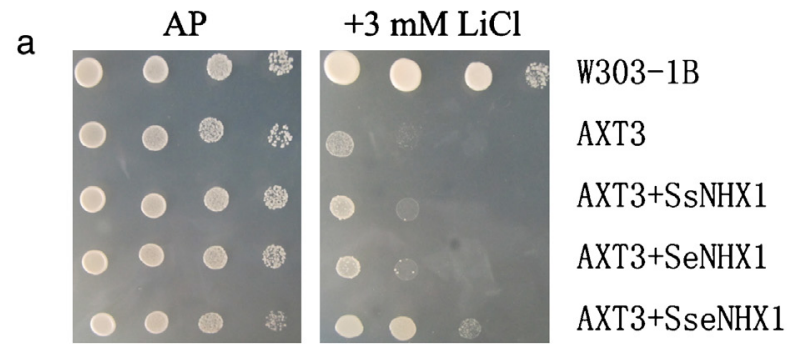

b
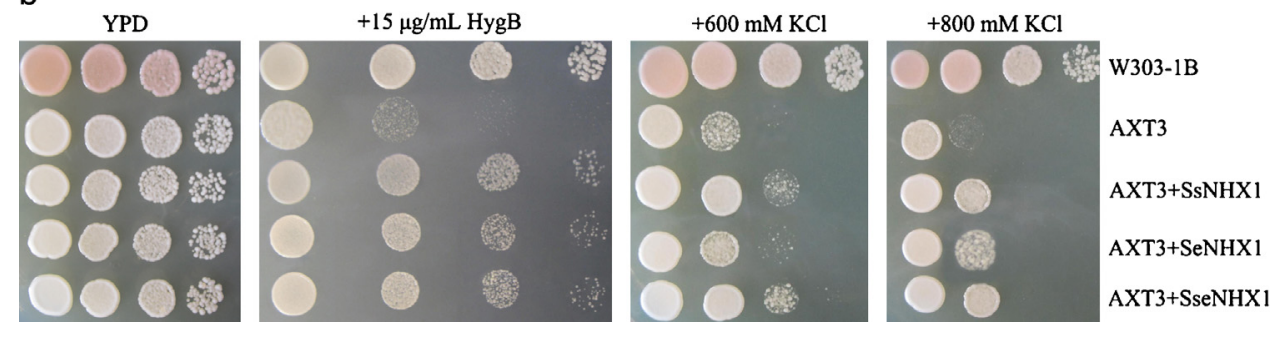

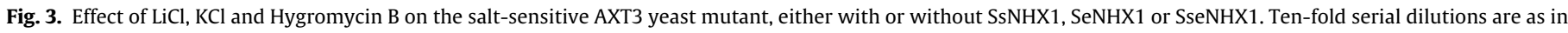

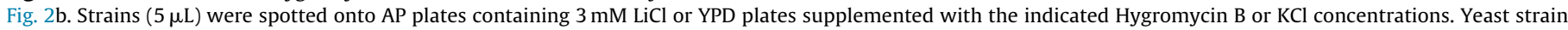
W303-1B was used as a positive control. Plates were incubated at $30^{\circ} \mathrm{C}$ and photographed after 3 days.

substitutions were all derived from SeNHX1, and two new mutations (A10Y and F117S) were introduced into the mutant SseNHX1 protein sequence. In addition, amino acid residues RIAY (from 210 to 213) existing in the corresponding positions of parental SsNHX1 were deleted. The SseNHX1 protein shares $97 \%$ and $90 \%$ identity to the SsNHX1 protein and SeNHX1 protein respectively, suggesting SseNHX1 is a result of a shuffled $\mathrm{Na}^{+} / \mathrm{H}^{+}$antiporter gene and could have the inherent functions. Two dimensional secondary structure of SseNHX1 protein sequence predicted by TMRPres2D showed 12 transmembrane domains (Fig. 4b). In addition, the binding site of amiloride ( ${ }^{86}$ LFFIYLLPPI ${ }^{95}$ ) that inhibits eukaryotic $\mathrm{Na}^{+} / \mathrm{H}^{+}$antiporters was present in the third domain while cation binding domains was predicted in fifth and sixth domain (Fig. 4b).

\section{Discussion}

DNA family shuffling is a powerful tool for directed molecular evolution in vitro which provides an effective method to obtain chimeric proteins with improved properties. In view of plant vacuolar $\mathrm{Na}^{+} / \mathrm{H}^{+}$antiporters playing important roles in cellular ion homeostasis and salt tolerance, the molecular evolution of $\mathrm{Na}^{+} / \mathrm{H}^{+}$ antiporters could potentially increase the application of these genes in salt tolerance-crop breeding and help us to understand the mechanism of transport and regulation of the $\mathrm{Na}^{+} / \mathrm{H}^{+}$antiporters. In this study, the templates SsNHX1 and SeNHX1 share a sequence identity of $86 \%$ and $87 \%$ at the DNA and protein levels, respectively. This level of identity is beneficial to the occurrence of crossover annealing events. Xu et al. (2010) reported that using AtNHX1 from Arabidopsis thaliana as the substrate for DNA shuffling resulted in the salt tolerance range not remarkable. Moreover, previous studies demonstrated that the effect of DNA shuffling by a single gene was significantly lower than that of DNA family shuffling (Crameri et al., 1998). S. salsa and S. europaea are two succulent euhalophyte in Chenopodiaceae. Unlike some other halophytic plants, S. salsa and S. europaea lack salt glands or salt bladders on their leaves. Thus, these plants must compartmentalize the toxic $\mathrm{Na}^{+}$in the vacuoles. Furthermore, S. europaea plants can accumulate up to $50 \% \mathrm{NaCl}$ of dry weight in shoot (Lv et al., 2012; Ushakova et al., 2005). Therefore, we used S. salsa and S. europaea as excellent candidates for the design of improved novel proteins by DNA family shuffling, which promotes the range of salt tolerance, thereby yielding chimeras with higher salt tolerance than parents.

Primer-less PCR is the key step in the process of DNA family shuffling. Taq Plus DNA polymerase was used in our protocol, which can effectively prevent the accumulation of spontaneous mutations in each of DNA family shuffling steps and contribute to fragments recombination in primer-less PCR. In addition, for expanding the pool of recombinants and reduction of parental background genes, skew primers consisting of one gene at the $5^{\prime}$ end and the other gene at the 3 '-end were added to amplify the parental genes (Fig. 1d). Another important factor of a successful DNA family shuffling lies in constructing a large enough mutant library ( $\approx 10^{5}$ shuffled gene mutants by a one-time operation) and finding an appropriate screening method. We applied yeast mutant as a heterologous expression system (Dreyer et al., 1999) to screen novel $\mathrm{Na}^{+} / \mathrm{H}^{+}$antiporter shuffled genes with higher $\mathrm{NaCl}$ tolerance. In terms of the establishment of the mutant library, we firstly establish a mutation plasmid library through the electric transformation of $E$. coli, and then transformed yeast with mutation plasmid library. Approximately 200 clones were obtained after the first screening, and finally one desired clone was chosen to be further characterized by comparison with the two parent $\mathrm{Na}^{+} / \mathrm{H}^{+}$antiporters after the second selection test (Fig. 2a). Yeast complementation tests showed that this shuffled clone exhibited higher tolerance to $\mathrm{NaCl}$ compared with that of the parents (Fig. 2b).

The sequencing results revealed a high degree of chimera genesis and a low rate of spontaneous mutation. In fact, a high proportion of parental sequences occur frequently in family shuffling libraries. At the amino acid level, the crossovers resulted in 14 mutations away from the most similar parent. Two-dimensional structure showed that cation-binding and amiloride-binding sites of the shuffled $\mathrm{Na}^{+} / \mathrm{H}^{+}$antiporter remained in transmembrane domains and were strictly conserved. It is important to notice that none of the random mutations and substitutions was found to locate in those strictly conserved regions. Our previous study demonstrated that the deletion of a part of the long C-terminal hydrophilic tail of SeNHX1 significantly inhibited the antiporter activity (Wu et al., 2014). Thus, it appeared that the six amino 
a

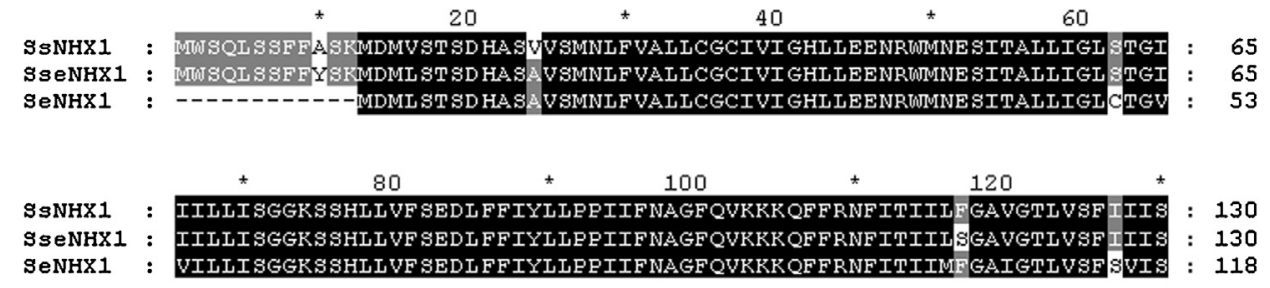

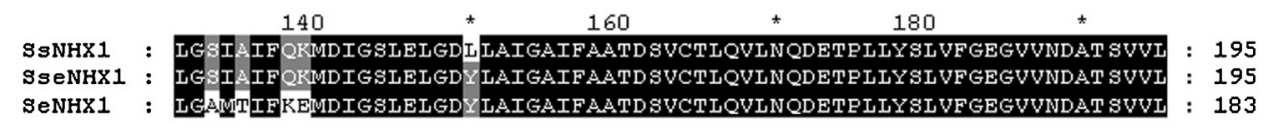

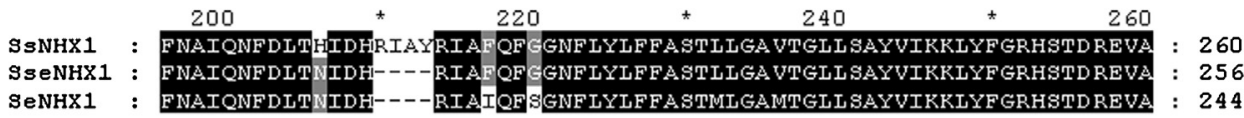

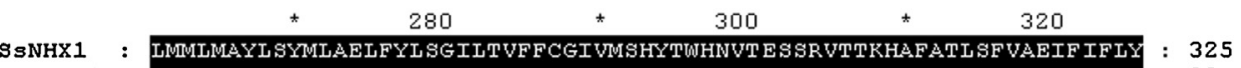
SseNHX1 : LMMLMAYLSYMLAELFYLSGILTVFFCGIVMSHYTWHNVTESSRVTTRHAFATLSFVAEIF IFLY : 321 SENHX1 : LMMIMAYLSYMLAELFYLSGILTVFFCGIVUSHYTWHNVTESSRVTTKHAFATLSFVAEIF LFLY : 309

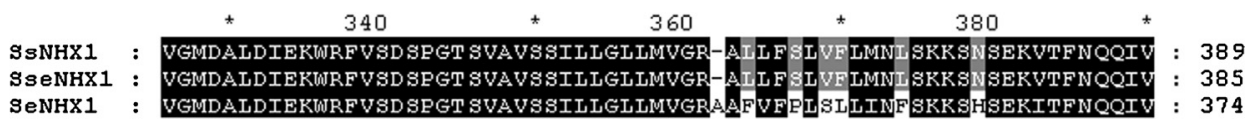

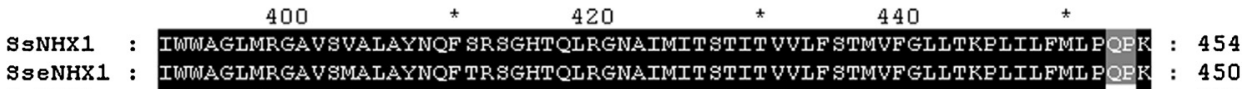

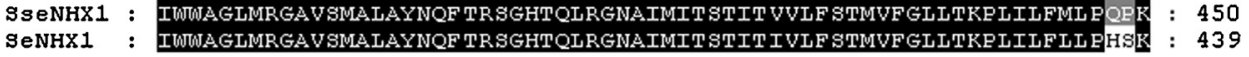

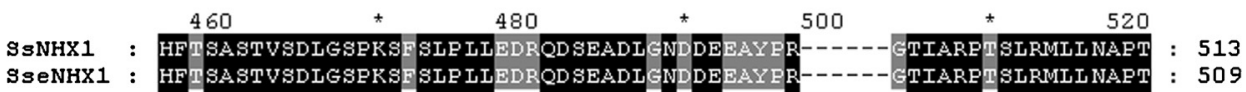

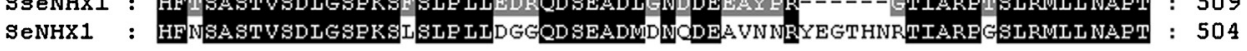

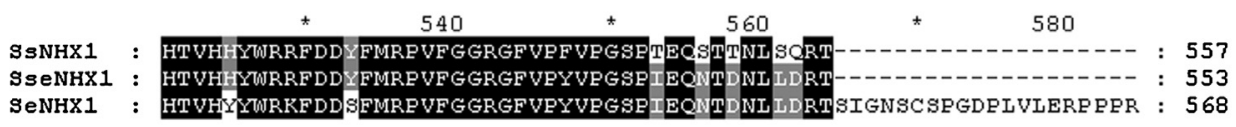

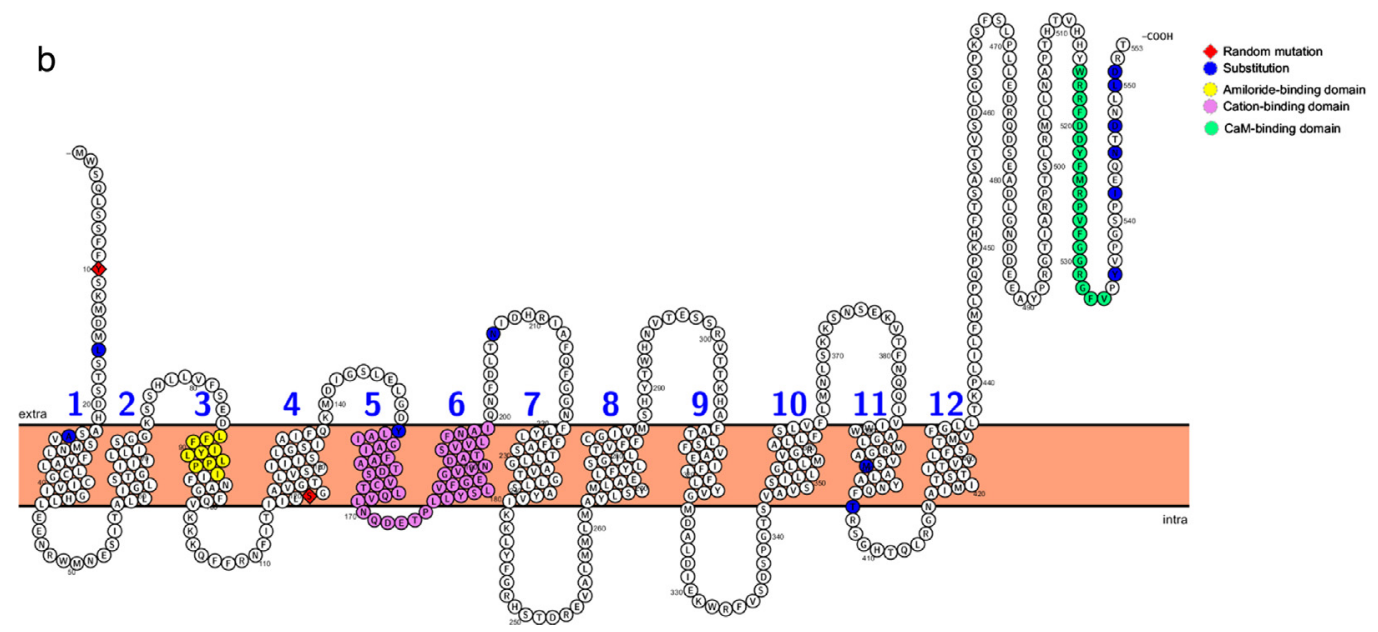

Fig. 4. Sequence analysis of SseNHX1. (a) Protein sequence alignment of the shuffled chimera SseNHX1 with the two parental proteins. Conserved residues are indicated in white on a black background. Sequence data were obtained from GenBank, and aligned using ClustalX and GeneDoc. The accession numbers of two parental $\mathrm{Na}^{+} / \mathrm{H}^{+}$antiporters are as follows: S. salsa (SsNHX1; AAP15178), Salicornia europaea (SeNHX1; AAN08157). (b) Proposed topological model of SseNHX1. The protein secondary structure was created by the program PROTTER, which was available online at http://wlab.ethz.ch/protter/start/. 
acid substitutions, localized in the long C-terminal hydrophilic tail, might favor $\mathrm{Na}^{+} / \mathrm{H}^{+}$exchange. Some progresses had been made regarding the regulation of the C-terminal region of the $\mathrm{Na}^{+} / \mathrm{H}^{+}$ antiporters in recent years. There are plenty of compelling precedents for the regulation of transport characteristics for $\mathrm{Na}^{+} / \mathrm{H}^{+}$ antiporter by modification of the transporter $\mathrm{C}$ terminus. In plasma membrane $\mathrm{Na}^{+} / \mathrm{H}^{+}$antiporter salt-overly-sensitive 1 (SOS1), the Cterminus contains an auto-inhibitory domain and the interaction of this region with another domain of SOS1 kept the transporter in a resting state with basal activity (Quintero et al., 2011). Hamada et al. (2001) also found that the deletion of a part of the long Cterminal hydrophilic tail significantly inhibited the carrier activity of Synechocystis Species PCC 6803 which homologous to SOS1. Li et al. (2009) reported that deletion of the hydrophilic C-terminus of AtNHX4 dramatically increased the hypersensitivity of transformants A similar phenomenon was found in Caragana korshinskii $\mathrm{Na}^{+} / \mathrm{H}^{+}$exchanger 1 (CkNHX1), indicting that the hydrophilic $\mathrm{C}$ terminus should be required for the activity of CkNHX1 (Yang et al., 2012). By contrast, the deletion of the hydrophilic $C$ terminus of AtNHX1 from Arabidopsis thaliana resulted in a dramatic increase in the relative rate of $\mathrm{Na}^{+} / \mathrm{H}^{+}$transport (Xu et al., 2010). Further studies indicated that the cation selectivity is regulated by calmodulin from within the vacuole in a $\mathrm{Ca}^{2+}$ - and $\mathrm{pH}$-dependent manner (Yamaguchi et al., 2005). Coincidentally, the C-terminus deletion of a novel plant vacuolar $\mathrm{Na}^{+} / \mathrm{H}^{+}$antiporter AtNHXS1 evolved by DNA shuffling improved $\mathrm{Na}^{+} / \mathrm{H}^{+}$exchange activity in yeast also suggesting a regulatory role of the $\mathrm{C}$-terminus on the antiporter activity (Xu et al., 2010).

Several studies have appeared that plant $\mathrm{Na}^{+} / \mathrm{H}^{+}$antiporters have ion specificity. Transgenic tomato overexpressing AtNHX1 showed increased antiport activity with both $\mathrm{Na}^{+}$and $\mathrm{K}^{+}$, albeit with lower specificity for $\mathrm{K}^{+}$(Zhang and Blumwald, 2001). By contrast, Qiu et al. (2004) reported that in tonoplast vesicles isolated from Arabidopsis, the vacuolar $\mathrm{Na}^{+} / \mathrm{H}^{+}$exchange was shown significant transport activity with $\mathrm{Na}^{+}$, and to a lesser extent with $\mathrm{Li}^{+}$transport, but not $\mathrm{K}^{+}$transport. In the halophytes Suaeda salsa, Populus euphratica (Ye et al., 2009), and Salicornia europaea, the $\mathrm{Na}^{+} / \mathrm{H}^{+}$antiport activity was greater than the $\mathrm{K}^{+} / \mathrm{H}^{+}$ exchange. Our data showed that the shuffled antiporter SseNHX1 had greatly selectivity to $\mathrm{Na}^{+}$, and to a relatively lesser extent to $\mathrm{K}^{+}$and $\mathrm{Li}^{+}$, which was consistent with the selectivity of halophytes.

In conclusion, the utility of DNA family shuffling of two halophytic $\mathrm{Na}^{+} / \mathrm{H}^{+}$antiporter genes with strong tolerance to create $\mathrm{Na}^{+} / \mathrm{H}^{+}$antiporter variants is an effective method in the enhancement of salt transport activity. One chimeric variant (SseNHX1) with 12 amino acid substitutions and 2 new mutations was obtained and demonstrated 1.2- and 1.4-fold improvement in sequestering $\mathrm{Na}^{+}$from the cells than parental genes, and is therefore a promising protein for the future development of transgenic crops resistant to high salt salinity. Further study of this hybrid antiporter, such as site-directed mutagenesis and modeling studies of molecular dynamics are needed to better understand the effects of the mutations present in the SseNHX1 variant on the transport activity.

\section{Acknowledgments}

We would like to thank Dr. José M. Pardo (Instituto de Recursos Naturalesy Agrobiologia, Spain) for kindly providing the yeast mutant strain AXT3. This work was supported financially by the National Natural Science Foundation of China (No. 31271419 and No. 31271793) and the National Science and Technology Key Project of China on GMO Cultivation for New Varieties (No. 2014ZX08003-002B).

\section{References}

Akbulut, N., Ozturk, M.T., Pijning, T., Ozturk, S.I., Gumusel, F., 2013. Improved activity and thermostability of Bacillus pumilus lipase by directed evolution. J. Biotechnol. 164, 123-129, http://dx.doi.org/10.1016/j.jbiotec.2012.12.016.

Blumwald, E., Aharon, G.S., Apse, M.P., 2000. Sodium transport in plant cells. Biochim. Biophys. Acta-Biomembr. 1465, 140-151, http://dx.doi.org/10.1016/ s0005-2736(00)00135-8.

Chen, H., An, R., Tang, J.-H., Cui, X.-H., Hao, F.-S., Chen, J., Wang, X.-C., 2007a. Over-expression of a vacuolar $\mathrm{Na}+\mathrm{H}+$ antiporter gene improves salt tolerance in an upland rice. Mol. Breeding 19, 215-225, http://dx.doi.org/10.1007/ s11032-006-9048-8.

Chen, M. et al., 2007b. Expression of OsNHX1 gene in maize confers salt tolerance and promotes plant growth in the field. Plant Soil and Environment 53, 490-498.

Crameri, A., Raillard, S.A., Bermudez, E., Stemmer, W.P.C., 1998. DNA shuffling of a family of genes from diverse species accelerates directed evolution. Nature 391, 288-291.

Dreyer, I., et al., 1999. Identification and characterization of plant transporters using heterologous expression systems. J. Exp. Bot. 50, 1073-1087, http://dx.doi.org/10.1093/jexbot/50.suppl_1.1073.

Fukuda, A., Chiba, K., Maeda, M., Nakamura, A., Maeshima, M., Tanaka, Y., 2004. Effect of salt and osmotic stresses on the expression of genes for the vacuolar $\mathrm{H}+$-pyrophosphatase, $\mathrm{H}+-$ ATPase subunit $\mathrm{A}$, and $\mathrm{Na}+/ \mathrm{H}+$ antiporter from barley. J. Exp. Bot. 55, 585-594, http://dx.doi.org/10.1093/jxb/erh070.

Fukuda, A., Nakamura, A., Hara, N., Toki, S., Tanaka, Y., 2011. Molecular and functional analyses of rice NHX-type $\mathrm{Na}+/ \mathrm{H}+$ antiporter genes. Planta 233, 175-188, http://dx.doi.org/10.1007/s00425-010-1289-4.

Gaxiola, R.A., Rao, R., Sherman, A., Grisafi, P., Alper, S.L., Fink, G.R., 1999. The Arabidopsis thaliana proton transporters. AtNhx1 and Avp1, can function in cation detoxification in yeast. Proc. Natl. Acad. Sci. U. S. A. 96, 1480-1485, http://dx.doi.org/10.1073/pnas.96.4.1480.

Gietz, R.D., Woods, R.A., 2002. Transformation of yeast by lithium acetate/singlestranded carrier DNA/polyethylene glycol method. Guide Yeast Genet. Mol. Cell Biol. Pt B 350, 87-96.

Hamada, A., Hibino, T., Nakamura, T., Takabe, T., 2001. Na+/H+ antiporter from Synechocystis species PCC 6803, homologous to SOS1, contains an aspartic residue and long C-terminal tail important for the carrier activity. Plant Physiol. 125, 437-446, http://dx.doi.org/10.1104/pp.125.1.437.

Hasegawa, P.M., Bressan, R.A., Zhu, J.K., Bohnert, H.J., 2000. Plant cellular and molecular responses to high salinity. Annu. Rev. Plant Physiol. Plant Mol. Biol. 51, 463-499, http://dx.doi.org/10.1146/annurev.arplant.51.1.463.

Kikuchi, M., Harayama, S., 2002. DNA shuffling and family shuffling for in vitro gene evolution. Methods Mol. Biol. (Clifton NJ) 182, 243-257.

Leidi, E.O., et al., 2010. The AtNHX1 exchanger mediates potassium compartmentation in vacuoles of transgenic tomato. Plant J. 61, 495-506, http://dx.doi.org/10.1111/j.1365-313X. 2009.04073.x.

Li, H.-T., Liu, H., Gao, X.-S., Zhang, H., 2009. Knock-out of Arabidopsis AtNHX4 gene enhances tolerance to salt stress. Biochem. Biophys. Res. Commun. 382 637-641, http://dx.doi.org/10.1016/j.bbrc.2009.03.091

$\mathrm{Li}, \mathrm{W}$., et al., 2011. The vacuolar $\mathrm{Na}+/ \mathrm{H}+$ antiporter gene SsNHX1 from the halophyte salsola soda confers salt tolerance in transgenic alfalfa (Medicago sativa L.). Plant Mol. Biol. Rep. 29, 278-290, http://dx.doi.org/10.1007/s11105-010-0224-y.

Lv, S., Nie, L., Fan, P., Wang, X., Jiang, D., Chen, X., Li, Y., 2012. Sodium plays a more important role than potassium and chloride in growth of Salicornia europaea. Acta Physiol. Plant. 34, 503-513, http://dx.doi.org/10.1007/s11738-0110847-0.

Montiel, V., Ramos, J., 2007. Intracellular $\mathrm{Na}+$ and $\mathrm{K}+$ distribution in Debaryomyces hansenii. Cloning and expression in Saccharomyces cerevisiae of DhNHX1. Fems Yeast Res. 7, 102-109, http://dx.doi.org/10.1111/j.1567-1364.2006.00115.x.

Niederhauser, B., Siivonen, J., Maatta, J.A., Janis, J., Kulomaa, M.S., Hytonen, V.P., 2012. DNA family shuffling within the chicken avidin protein family - a shortcut to more powerful protein tools. J. Biotechnol. 157, 38-49, http://dx.doi.org/10.1016/j.jbiotec.2011.10.014.

Omasits, U., Ahrens, C.H., Mueller, S., Wollscheid, B., 2014. Protter: interactive protein feature visualization and integration with experimental proteomic data. Bioinformatics 30, 884-886, http://dx.doi.org/10.1093/bioinformatics/btt607.

Qiu, Q.S., Guo, Y., Quintero, F.J., Pardo, J.M., Schumaker, K.S., Zhu, J.K., 2004. Regulation of vacuolar $\mathrm{Na}+\mathrm{H}+$ exchange in Arabidopsis thaliana by the salt-overly-sensitive (SOS) pathway. J. Biol. Chem. 279, 207-215, http://dx.doi.org/10.1074/jbc.M307982200.

Quintero, F.J., Blatt, M.R., Pardo, J.M., 2000. Functional conservation between yeast and plant endosomal $\mathrm{Na}^{+} / \mathrm{H}^{+}$antiporters1. FEBS Lett. 471, 224-228, http://dx.doi.org/10.1016/S0014-5793(00)01412-5

Quintero, F.J., et al., 2011. Activation of the plasma membrane $\mathrm{Na} / \mathrm{H}$ antiporter Salt-Overly-Sensitive 1 (SOS1) by phosphorylation of an auto-inhibitory C-terminal domain. Proc. Natl. Acad. Sci. U. S. A. 108, 2611-2616, http://dx.doi.org/10.1073/pnas.1018921108.

Quintero, F.J., Ohta, M., Shi, H.Z., Zhu, J.K., Pardo, J.M., 2002. Reconstitution in yeast of the Arabidopsis SOS signaling pathway for $\mathrm{Na}+$ homeostasis. Proc. Natl. Acad. Sci. U. S. A. 99, 9061-9066, http://dx.doi.org/10.1073/pnas.132092099.

Rosic, N.N., Huang, W., Johnston, W.A., DeVoss, J.J., Gillam, E.M.J., 2007. Extending the diversity of cytochrome P450 enzymes by DNA family shuffling. Gene 395, 40-48, http://dx.doi.org/10.1016/j.gene.2007.01.031.

Shi, H.Z., Quintero, F.J., Pardo, J.M., Zhu, J.K., 2002. The putative plasma membrane $\mathrm{Na}+/ \mathrm{H}+$ antiporter SOS1 controls long-distance $\mathrm{Na}+$ transport in plants. Plant Cell 14, 465-477, http://dx.doi.org/10.1105/tpc.010371. 
Stemmer, W.P., 1994. DNA shuffling by random fragmentation and reassembly: in vitro recombination for molecular evolution. Proc. Natl. Acad. Sci. U. S. A. 91, 10747-10751.

Suen, W.C., Zhang, N.Y., Xiao, L., Madison, V., Zaks, A., 2004. Improved activity and thermostability of Candida antarctica lipase B by DNA family shuffling. Protein Eng. Design Selection 17, 133-140, http://dx.doi.org/10.1093/protein/ gzh017.

Thompson, J.D., Gibson, T., Higgins, D.G., 2002. Multiple sequence alignment using ClustalW and ClustalX. Curr. Protocols Bioinformatics, 2.3.1-2.3.22.

Ushakova, S.A., Kovaleva, N.P., Gribovskaya, T.V., Dolgushev, V.A., Tikhomirova, N.A., 2005. Effect of $\mathrm{NaCl}$ concentration on productivity and mineral composition of Salicornia europaea as a potential crop for utilization $\mathrm{NaCl}$ in LSS. In: Hasenstein, K.H., Levine, H., Porterfield, D.M. (Eds.), Space Life Sciences: Gravity-Related Effects on Plants and Spaceflight and Man-Made Environments on Biological Systems, vol 36. Advances in Space Research, vol 7., pp. 1349-1353, http://dx.doi.org/10.1016/j.asr. 2004.09.017.

Wang, J., Zhang, Q., Huang, Z., Liu, Z., 2013a. Directed evolution of a family 26 glycoside hydrolase: endo-beta-1, 4-mannanase from Pantoea agglomerans A021. J. Biotechnol. 167, 350-356, http://dx.doi.org/10.1016/j.jbiotec.2013.06. 019.

Wang, X.-F., Li, Q.-Z., Bao, T.-W., Cong, W.-R., Song, W.-X., Zhou, X.-W., 2013b. In vitro rapid evolution of fungal immunomodulatory proteins by DNA family shuffling. Appl. Microbiol. Biotechnol. 97, 2455-2465, http://dx.doi.org/ 10.1007/s00253-012-4131-z.

Wu, G.X., Wang, G., Ji, J., Tian, X.W., Gao, H.L., Zhao, Q., Li, J., Wang, Y.R., 2014 Hydrophilic C terminus of Salicornia europaea vacuolar $\mathrm{Na}^{+} / \mathrm{H}^{+}$antiporter is necessary for its function. J. Genet. 93, 425-430.

Xu, K., Zhang, H., Blumwald, E., Xia, T., 2010. A novel plant vacuolar $\mathrm{Na}+/ \mathrm{H}+$ antiporter gene evolved by DNA shuffling confers improved salt tolerance in yeast. J. Biol. Chem. 285, 22997-23004, http://dx.doi.org/10.1074/jbc.M109.073783.
Yamaguchi, T., Aharon, G.S., Sottosanto, J.B., Blumwald, E., 2005. Vacuolar Na+/H+ antiporter cation selectivity is regulated by calmodulin from within the vacuole in a Ca2+- and pH-dependent manner. Proc. Natl. Acad. Sci. U. S. A. 102 , 16107-16112, http://dx.doi.org/10.1073/pnas.0504437102.

Yang, D.-H., et al., 2012. Enhanced tolerance to $\mathrm{NaCl}$ and $\mathrm{LiCl}$ stresses by over-expressing Caragana korshinskii sodium/proton exchanger 1 (CkNHX1) and the hydrophilic $\mathrm{C}$ terminus is required for the activity of CkNHX1 in Atsos3-1 mutant and yeast. Biochem. Biophys. Res. Commun. 417, 732-737, http://dx.doi.org/10.1016/j.bbrc.2011.12.023.

Ye, C.-Y., Zhang, H.-C., Chen, J.-H., Xia, X.-L., Yin, W.-L., 2009. Molecular characterization of putative vacuolar NHX-type $\mathrm{Na}+\mathrm{H}+$ exchanger genes from the salt-resistant tree, Populus euphratica. Physiol. Plant. 137, 166-174, http://dx.doi.org/10.1111/j.1399-3054.2009.01269.x.

Yokoi, S., Quintero, F.J., Cubero, B., Ruiz, M.T., Bressan, R.A., Hasegawa, P.M. Pardo, J.M., 2002. Differential expression and function of Arabidopsis thaliana $\mathrm{NHX} \mathrm{Na}+/ \mathrm{H}+$ antiporters in the salt stress response. Plant J. 30, 529-539, http://dx.doi.org/10.1046/j.1365-313X. 2002.01309.x.

Zhang, H.X., 2001. Engineering salt-tolerant Brassica plants: characterization of yield and seed oil quality in transgenic plants with increased vacuolar sodium accumulation. Proc. Natl. Acad. Sci. 98, 12832-12836, http://dx.doi.org/10.1073/pnas.231476498.

Zhang, H.-X., Blumwald, E., 2001. Transgenic salt-tolerant tomato plants accumulate salt in foliage but not in fruit. Nat. Biotech. 19, 765-768.

Zhang, H., Liu, Y., Xu, Y., Chapman, S., Love, A., Xia, T., 2012. A newly isolated Na+/H+ antiporter gene, DmNHX1, confers salt tolerance when expressed transiently in Nicotiana benthamiana or stably in Arabidopsis thaliana. Plant Cell Tissue Organ Cult. 110, 189-200, http://dx.doi.org/10.1007/s11240-012-0142-9

Zhao, H., Arnold, F.H., 1997. Optimization of DNA shuffling for high fidelity recombination. Nucleic Acids Res. 25, 1307-1308, http://dx.doi.org/10.1093 nar/25.6.1307. 